with positive smears histological sections failed to reveal asbestos bodies in over $50 \%$. Histological evidence of minimal asbestosis was found in 10 cases. There were no cases of classical asbestosis. The series includes one case of mesothelioma of pleura. There was no significant excess of positive smears in patients dying from gastrointestinal or lung carcinoma. The incidence was higher in patients living in urban areas $(25.6 \%)$ than in those from rural areas $(3.5 \%)$. Twenty-nine patients definitely or probably were exposed to asbestos dust at work and two further patients had non-occupational exposure. Neighbourhood contamination with asbestos dust is probably not important in this series. When compared with a series of 23 cases of mesothelioma of pleura or peritoneum, 21 (91\%) of which showed asbestos bodies in histological sections of lung, the greater incidence of asbestos bodies in the cases of mesothelioma is statistically highly significant.

This survey was suggested by Professor A. G. Heppleston, and I am indebted to him for valuable criticism and advice during the work. My thanks are also due to Professor D. J. Newell for statistical advice, to the late Mr. L. Hall and Mr. W. Brine for assistance in preparing the smears, and to Miss Joyce Ward for assistance in interviewing patients' relatives.

\section{REFERENCES}

Anjilvel, L., and Thurlbeck, W. M. (1966). Canad. med. Ass. 7., 95, 1179.

Ashcroft, T. (1968). In preparation.

Cauna, D., Totten, R. S., and Gross, P. (1965). 7. Amer. med. Ass., 192, 371 .

Doll, R. (1955). Brit. F. industr. Med., 12, 81.

Elmes, P. C., McCaughey, W. T. E., and Wade, O. L. (1965). Brit. med. 7., $1,350$.

Enticknap, J. B., and Smither, W. J. (1964). Brit. F. industr. Med., 21, 20.

Heppleston, A. G. (1953). 7. Path. Bact., 66, 235.

Hourihane, D. O'B. (1964). Thorax, 19, 268.

Meurman, L. (1966). Acta path. microbiol. scand., Suppl. No. 181.

Owien, W. G. (1964). Brit. med. 7., 2, 214.

Roberts, G. H. (1967). F. clin. Path., 20, 570.

Selikoff, I. J., Churg, J., and Hammond, E. C. (1964). F. Amer. med. Ass., 188, 22.

Selikoff, I. J., Churg, J., and Hammond, E. C. (1965). New Engl. Y. Med., 272,560

Thomson, J. G. (1962). S. Afr. med. 3., 36, 759.

Thomson, J. G., and Graves, W. M., jun. (1966). Arch. Path., 81, 458. Thomson, J. G., Kaschula, R. O. C., and MacDonald, R. R. (1963). S. Afr. med. $\ddot{\mathfrak{f}} ., 37,77$.

Tylecote, F. E., and Dunn, J. S. (1931). Lancet, 2, 632.

Wagner, J. C., Sleggs, C. A., and Marchand, P. (1960). Brit. 7. industr. Med., 17, 260 .

Williams, F. (1934). Lancet, 2, 541.

\title{
Method for Estimating Objectively the Comparative Merits of Biological Tests of Lead Exposure
}

\author{
M. K. WILLIAMS, ${ }^{*}$ M.A., B.M., D.I.H. ; E. KING, $\dagger$ B.SC. ; JOAN WALFORD, $\ddagger$ A.I.S
}

Brit. med. F., 1968, 1, 618-621

Many biological tests are used for the diagnosis of lead-poisoning and for the control of lead absorption in industry. The punctate basophil count and haemoglobin (Legge and Goadby, 1912), urinary lead (Belknap, 1935), blood lead (American Public Health Association, 1943), urinary coproporphyrin (de Langen and Ten Berg, 1948), and urinary $\delta$-aminolaevulinic acid (ALA) (Haeger-Aronsen, 1960) have been recommended, and are still used (Zielhuis, 1961; Ministry of Labour, 1964 Moncrieff et al., 1964 ; Dagg et al., 1965 ; Cramér and Selander, 1965 ; Williams, 1966).

The comparative merits of these tests of lead exposure have been estimated objectively by an original statistical method, with use of data obtained from a survey of lead workers.

\section{The Survey}

The survey was made in a lead-acid battery factory. Personal samplers (Casella \& Co., 1966 ; Williams, 1967) were worn on the coat lapel by a number of workers every shift for two weeks to obtain accurate estimates of the lead-in-atmosphere concentration to which they were exposed. During the second week blood lead, urinary lead, urinary coproporphyrin, urinary ALA, the punctate basophil count, and haemoglobin were estimated daily. Lead workers were sought whose exposure to lead was as constant as possible and had continued long enough for the biological variables to be fairly stable. The selection criteria adopted were that there had been no change of job within the last year; no recent sickness, holiday, or other

- Senior Lecturer, Department of Occupational Health and Applied Physiology, London School of Hygiene and Tropical Medicine, London W.C.1.

t Director of the Occupational Hygiene Service, Nuffield Department of Occupational Health, Manchester University.

Statistician, Department of Occupational Health and Applied Physiology, Lendon School of Hygiene and Tropical Medicine, London W.C.1. absence; and no change in overtime or in productivity for six months. The jobs of men selected represented the full range of lead exposure available, and did not entail wearing respirators. Of the men in the factory who fulfilled these criteria the following 40 were chosen: all the six machine pasters (M), all the eight hand pasters $(\mathrm{H})$, all the six hand casters $(\mathrm{C})$, the first 10 to volunteer of the 15 forming men $(F)$, and the first 10 to volunteer of 18 controls $(\mathrm{O})$ from departments making plastics. The element of self-selection in the forming men and controls was thought to be unimportant because the men knew there was no likelihood of their job or their wages being affected, or an illness discovered, as a result of entering the survey.

The men were studied in four groups of 10. Each man wore one of ten personal samplers for the whole of each shift, from clocking in to clocking out. Different samplers were worn daily, in a randomized sequence. I.1 the second week daily samples for blood lead by venepuncture, urinary lead, punctate basophil count, and haemoglobin were collected between 10 and 11 a.m. Another urinary sample for coproporpyhrin and ALA was collected between 12 noon and 1 p.m.

Blood lead and urinary lead samples were analysed by a modification of the method of King and Thompson (1961), and lead-in-air samples were estimated polarographically by one of us (E. K.). Urinary coproporphyrin was estimated by the semiquantitative method of Donath (1956), and urinary ALA by a simplification (Williams and Few, 1967) of the method of Mauzerall and Granick (1956), by one of us (M. K. W.). Punctate basophil counts were made by an experienced technician using Lane's (1949) method, and haemoglobin estimations were undertaken by an experienced State-registered nurse using the M.R.C. grey wedge photometer. The collection of samples and the analytical methods, together with the men's jobs, have been described in detail elsewhere (Williams, 1967).

The cost of each test was estimated as follows. The time off work of each man and the time of the medical staff to collect 
10 samples for each test were observed. The cost of analysis of each test, the cost of overheads, and the total cost per sample were then calculated by the accountant of the factory.

\section{Results}

Of the 40 men studied one withdrew after eight days owing to a foot injury. The results obtained from the remaining 39 were as follows.

Of the 390 total possible lead-in-air results 387 were accepted. Two lead-in-air samples from a control were missed owing to sickness absence and one lead-in-air result was more than 10 standard deviations higher than the mean of the other nine samples from the same man, so was rejected as unreliable.

Each of the biological tests had a possible total of 195 results. Of the 195 blood lead samples collected all 50 samples from the men in the first group (comprising six casters and four hand pasters) were rejected because of contamination of the sample bottles; and one sample was lost during analysis. The remaining 144 results were accepted, though one was collected two hours late owing to sickness absence.

A total of 182 urinary lead results were accepted. One sample was missed owing to sickness absence, one was lost during analysis, and two results were rejected as unreliableeach was mare than three times the respective mean of the other results from the same men. The remaining results were corrected to a standard specific gravity of 1024 (Levine and Fahy, 1945; Elkins and Pagnotto, 1965) except for nine samples which had specific gravities less than 1010 and were rejected (Barnes, 1939 ; Webster, 1941 ; Molyneux, 1964).

Of the punctate basophil slides 19 were reported as too dusty to read. The remainder were accepted.

None of the samples for urinary coproporphyrin and ALA and for haemoglobin was missed. All the results were accepted.

\section{Statistical Method}

If two variables $x$ and $y$ are associated (Fig. 1), and if measurements of $y$ are used to estimate $x$, the merit $z$ of a measurement will vary (1) directly as the slope of the regression of $y$ on $\mathbf{x}$; (2) inversely at the variation of $y$ about the regression line. That is,

$$
z \propto \frac{b}{s},
$$

where $b$ is the regression coefficient of $y$ on $x$ and represents the average change in $y$ for a change of one unit in $x$, and $s$ is the standard deviation of $y$ about the regression line. Also, if the

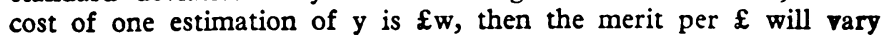
(3) inversely as $\sqrt{ } w$. That is,

$$
z \propto \frac{b}{s \sqrt{ } w} .
$$

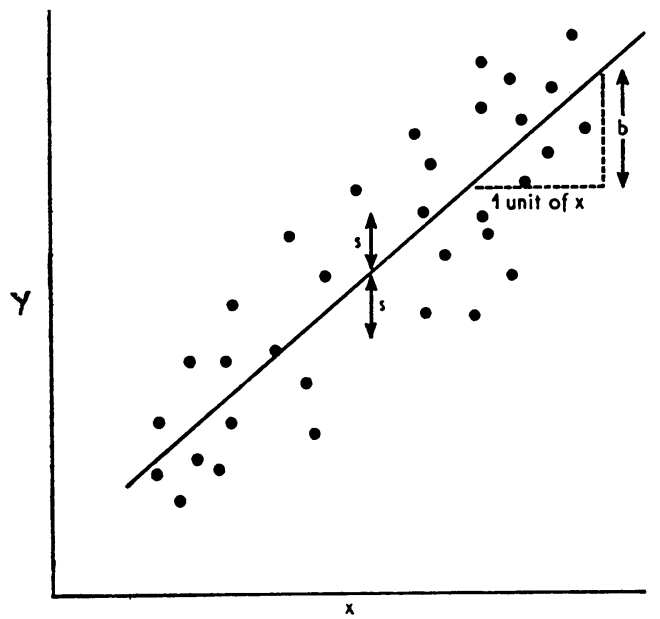

Fig. 1.-Regression line of $y$ on $x$ with regression coefficient $b$ and standard deviation $s$ of $y$ about the regression line.
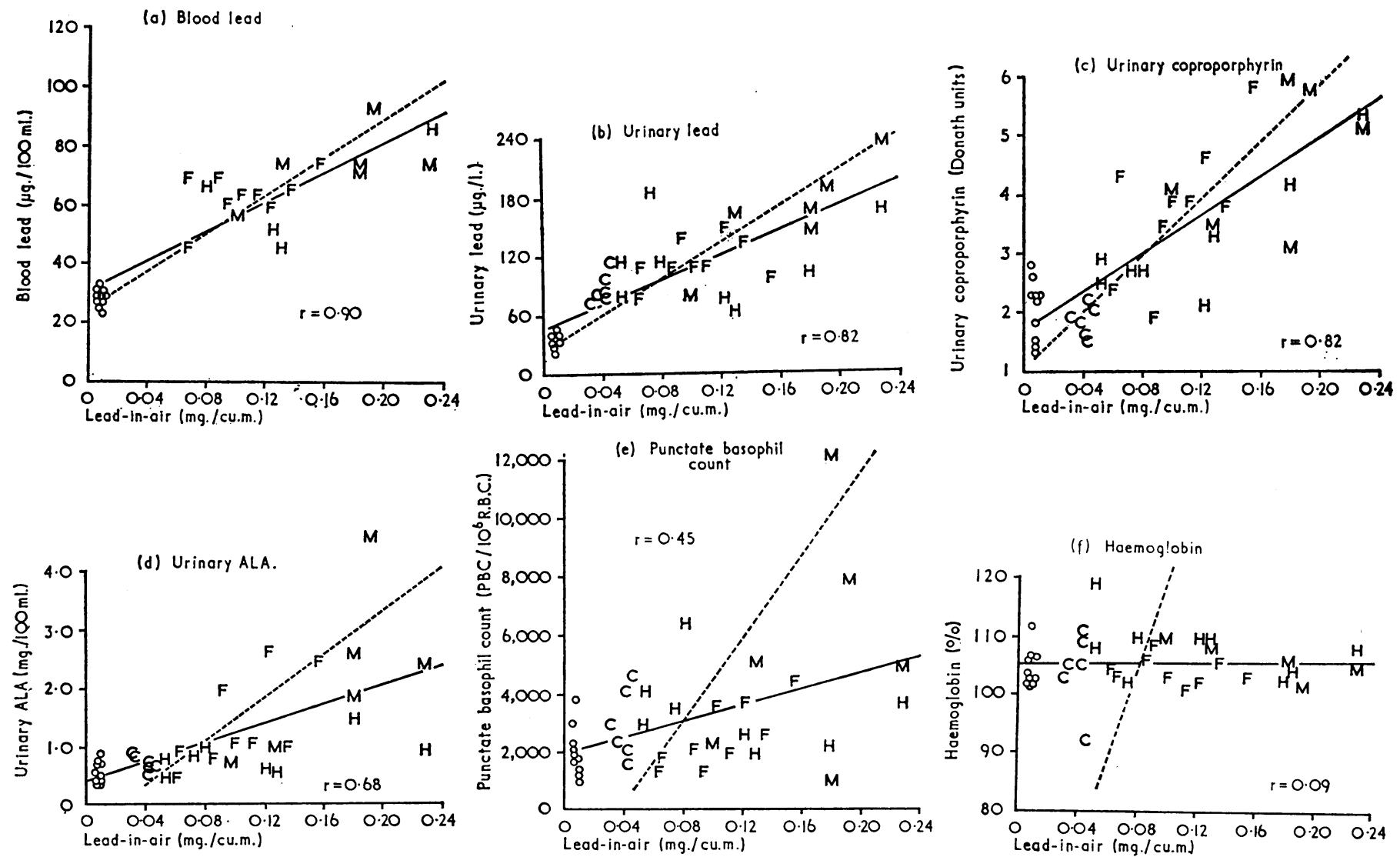

FIg. 2.-Association of each biological test with lead-in-air. Scatter diagrams made by plotting the individual mean values of each biological test with the individual mean lead-in-air concentration. Values are plotted as the initial letter of the man's department, excepting values from controls which are shown as noughts. Regression lines and correlation coefficients are also shown. The regression lines of each biological test on lead-in-air concentration are shown as solid lines. 


\section{Comparative Merit per Test}

The mean mass of lead found on the personal sampler filter discs of each man was divided by the mean volume of air sampled in eight hours to obtain the "mean eight-hour leadin-air concentration." The mean values of the biological tests of each man were calculated.

Scatter diagrams were made by plotting the co-ordinate points of the mean values of each biological test and the mean eighthour lead-in-air concentration, as shown in Fig. 2. Co-ordinate points are plotted as the initial letter of the men's departments, except for the controls, which are shown as noughts. Both regression lines are shown in each case, that of the biological test on lead-in-air concentration being shown as a solid line.

The regression coefficients $b_{1}, b_{2}, \ldots$ of each biological test on lead-in-air concentration and the standard deviations about the regression lines $s_{1}, s_{2}, \ldots$ are shown in Table I.

TABlE I.-Regression Coefficient (b), and Standard Deviation (s) About the Regression Line, of Each Biological Test on the Mean Eighthour Lead-in-air Concentration (mg. Pb/cu.m.)

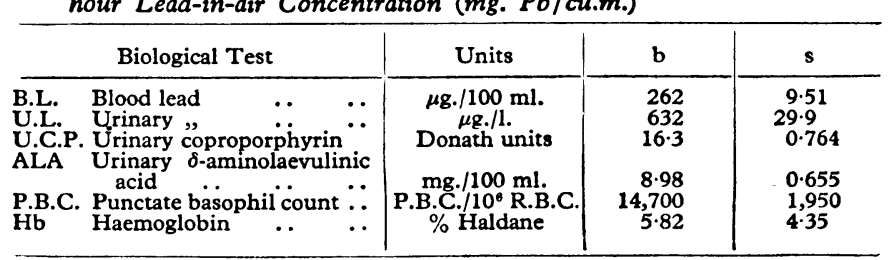

The comparative merits $z_{1}, z_{2}, \ldots$ were calculated as $\frac{b_{1}}{s_{1}}, \frac{b_{2}}{s_{2}}, \ldots$ with standard error, S.E. $\left(z_{1}\right)=$

$$
\sqrt{\frac{1}{\sum(x-\bar{x})^{2}}+\frac{b_{1}{ }^{2}}{2 n s_{1}{ }^{2}}} i=1,2, \ldots
$$

where $n=$ the number of observations. The values of $z$, S.E.(z), and the $95 \%$ confidence limits of $z$ are shown in Table II.

TABLE II.-Comparative Merit (z) of Each Biological Test with Standard Error (S.E. (z)), and $95 \%$ Confidence Limits

\begin{tabular}{|c|c|c|c|c|}
\hline \multicolumn{2}{|c|}{ Biological Test } & $\mathbf{z}$ & S.E.(z) & 95\% C.L. \\
\hline $\begin{array}{l}\text { B.L. } \\
\text { U.L. } \\
\text { U.C.P. } \\
\text { AL.A } \\
\text { P.B.C. } \\
\text { Hb }\end{array}$ & $\begin{array}{ll}\because & \because \\
\because & \because \\
\cdots & \\
\cdots & \end{array}$ & $\begin{array}{c}27.6 \\
21.1 \\
21 \cdot 3 \\
13.7 \\
7.54 \\
1.34\end{array}$ & $\begin{array}{l}4.47 \\
3.46 \\
3.47 \\
2.91 \\
2.59 \\
2.44\end{array}$ & $\begin{array}{ccc}18.6 \text { and } & 36.5 \\
14.2 & 28.0 \\
14.4 & 28.2 \\
7.88 & 29.5 \\
2.37 & 12.7 \\
-3.58 & 0.18\end{array}$ \\
\hline
\end{tabular}

The significance of the differences between the comparative merits of pairs of the biological tests is shown in Table III. ${ }^{1}$ The significance tests were based on the assumption that the distribution of $z$ is approximately normal. The results do not

TABle III.-Differences Between Comparative Merits of Pairs of Biological Tests, Standard Errors of the Differences (S.E. (d) ) and Probabilities $(P)$ of the Differences Occurring by Chance

\begin{tabular}{lll|c|c|c}
\multicolumn{2}{c|}{ Biological Tests } & Difference & S.E.(d) & P \\
\hline B.L. : U.L. &. &. & 6.47 & 5.65 & $>0.05$ \\
B.L.: U.C.P. &. &. & 6.30 & 5.66 & $>0.05$ \\
B.L.: ALA &. &. & 13.87 & 5.34 & $<0.01$ \\
B.L. : P.B.C. &. &. & 20.04 & 5.17 & $<0.001$ \\
U.L. : ALA &. &. & 7.40 & 4.52 & $>0.05$ \\
U.L. : P.B.C. &. &. & 13.56 & 4.32 & $<0.01$ \\
U.C.P. : ALA &.. &. & 7.57 & 4.53 & $>0.05$ \\
U.C.P. : P.B.C. &.. & 13.73 & 4.33 & $<0.01$
\end{tabular}

allow for the fact that since each $z$ is based on data from the same men they are not independent. Since the relation would be positive the standard error of the difference is an overestimate and the probability of a given difference occurring by chance may be smaller than that shown.

${ }^{1}$ When $z$ is calculated by using individual daily readings the order of the biological tests and the results of the significance tests remain unchanged.
The comparative merit of blood lead was greatest. With the 0.05 level as the criterion of statistical significance, it was significantly greater than the merits of urinary ALA $(P<0.01)$ and punctate basophil count $(P<0.001)$, but not significantly greater than the merits of urinary lead and coproporphyrin. The latter were next greatest and approximately equal. Both were significantly greater $(P<0.01)$ than the merit of punctate basophil count but were not significantly greater than the merit of urinary ALA. Urinary ALA was of intermediate merit and punctate basophil count of little merit. Haemoglobin appeared to be of no value ; the merit was very small and though expected to be of negative sign was positive.

\section{Comparative Merit per Unit Cost}

From (3) above the comparative merits of the biological tests may be expressed in terms of cost. Results obtained when using the cost estimated by the cost accountant of the factory are shown in Table IV. The merit per unit cost of urinary coproporphyrin is greater at the $5 \%$ level of significance than that of every other biological test.

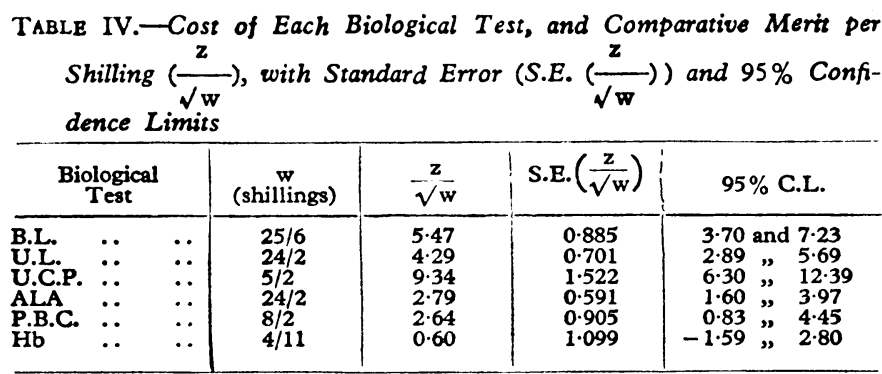

\section{Discussion}

The results of the survey have been used to determine the comparative merits of the biological tests for estimating lead exposure, measured by personal sampler. Since there are differences between men in minute-volume and in nose-lapel distance, and differences in the particle size distribution of the fume and dust to which the men are exposed, lead absorption will not be perfectly correlated with this measurement of exposure. It is of interest, however, that Fig. 2 does not indicate any marked departmental differences. Also, since there are metabolic differences between men, lead-poisoning will not correlate perfectly with absorption. To determine the comparative merits of the tests for estimating lead absorption, or lead-poisoning, surveys could be made in which these factors were measured together with the biological tests. For example, the symptoms of lead-poisoning can be assessed on a numerical scale to obtain a "score" as shown by Cramér and Selander (1965). "Absorption" is difficult to define-and therefore difficult to measure. It is possible to argue a priori that since lead entering the body passes into the blood before passing to other tissues, and before causing symptoms, blood lead must per se be the best biological test for estimating absorption. But there seems to be little objective evidence in the literature to substantiate this ; more often, blood lead is assumed to be prima facie evidence of absorption and the other biological tests are compared with it (U.S. Public Health Service, 1963).

Also, the lead exposure studied was at a safe level, and stable. At unsafe levels the merits of the tests will be different. Haemoglobin, for example, falls as exposure becomes excessive and will cease to have zero merit at such levels. When exposure is unstable, in industries such as shipbreaking or in some cases of domestic poisoning, the merits of the tests may again be different. Thus Kehoe (1962) stated that urinary lead undergoes relatively prompt change after changes in exposure, while blood lead shows an appreciable delay. Surveys to determine 
the lag and "merit" of each test when exposure varies would be of interest.

The calculated cost of a biological estimation depends not only on the analysis performed but also on the number of samples analysed annually, the cost of obtaining the samples, the efficiency of the organization, and the method of costing. The costs given will not necessarily be found elsewhere. But the low cost and simplicity of Donath's (1956) semiquantitative method of measuring urinary coproporphyrin in contrast to determinations of blood lead and urinary lead may be emphasized.

The merit per unit cost may be useful for obtaining the maximum cost-effectiveness from a given budget for the control of the lead exposure of a group of lead workers (King and Thompson, 1961). The cost will be of secondary importance for deciding what the budget should be and for diagnosing lead-poisoning in hospital and controlling the lead exposure of individuals, as distinct from groups, in industry.

It may be argued that industrial lead exposure should be measured solely by personal lead-in-air sampling. However, the personal sampler may be used conveniently to measure lead exposure over only relatively short periods of time, whereas the biological tests " integrate" exposure over longer periods of time. Since exposure is never constant, personal lead-in-air samples need to be taken more frequently than biological tests, and since the personal sampler is no more acceptable to the worker than biological tests little advantage would be gained. Biological tests have other advantages over personal samplers. They may be used where respirators are worn, they reflect the worker's domestic as well as industrial exposure, and they are simpler to organize on a large scale.

The method used is thought to be original. The possibility of other application arises as the medical and social sciences become more quantitative.

\section{Summary}

An original method for estimating objectively the comparative merits of biological tests was used to assess some of the biological tests of lead exposure. Thirty-nine lead workers and controls whose lead absorption was fairly stable wore personal samplers every working day for two weeks to obtain estimates of their lead exposure. During the second week blood lead, urinary lead, urinary coproporphyrin, urinary $\delta$-aminolaevulinic acid (ALA), the punctate basophil count, and haemoglobin were each estimated daily.

Blood lead was found to have the greatest merit, followed by urinary lead and urinary coproporphyrin together. Urinary ALA was of less merit, the punctate basophil count of little merit, and haemoglobin of no merit at the level of exposurc studied.

We are especially grateful to the 40 employees of the Electric Power Storage Company Ltd., Dagenham, who took part in the survey. We are also grateful to Professor P. Armitage for the method used to estimate the comparative merits of the biological tests ; to Mr. J. Few, Mr. T. J. Forward, and Mr. M. Mohuiddin for assistance with urinary ALA estimations; to Sister Margaret Smith for haemoglobin estimations; to Mrs. Lilian White for punctate basophil counts ; to Mr. J. Hay for assistance with personal samplers ; to $\mathrm{Mr}$. J. White for the cost analysis ; and to Miss Linda South for computing assistance. Finally, we are indebted to Dr. D. Malcolm and the Directors of the Electric Power Storage Company, Ltd., for permission to undertake the survey, and for financial assistance; and to many other members of the company for help and co-operation.

\section{REFERENCES}

American Public Health Association (1943). Occupational Lead Exposure and Lead Poisoning, report prepared by the committee on lead poisoning of the Industrial Hygiene Section of the A.P.H.A. New York.

Barnes, E. C. (1939). F. industr. Hyg., 21, 464.

Barnes, E. C. (1939). F. industr. Hyg., 21, 464. 205.

Belknap, E. L. (1935). F. Amer. med. Ass., 34, 205. Leaflet 930/5/AR London.

Cramér, K., and Selander, S. (1965). Brit. f. industr. Med., 22, 311.

Dagg, J. H., Goldberg, A., Lochhead, A., and Smith, J. A. (1965). Quart. f. Med., 34, 163.

Donath, W. F. (1956). Arh. Hig. Rada, 7, 77

Elkins, H. B., and Pagnotto, L. D. (1965). Amer. industr. Hyg. Ass. \}., 26, 456.

Haeger-Aronsen, Birgitta (1960). Scand. f. clin. Lab. Invest., 12, Suppl.

Kehoe, R. A. (1962). In Industrial Hygiene and Toxicology, edited by F. A. Patty, 2nd ed., vol. 2, p. 941. New York.

King, E., and Thompson, A. R. (1961). Ann. occup. Hyg., 3, 247.

Lane, R. E. (1949). Brit. ๆ. industr. Med., 6, 125

Langen, C. D. de, and Ten Berg, J. A. G. (1948). Acta med. scand., 130, 37. Abstract in f. Amer. med. Ass., 138, 244.

Legge, T. M., and Goadby, K. W. (1912). Lead Poisoning and Lead Absorption, the Symptoms, Pathology and Prevention, with Special Aeference to their Industrial Origin and an Account of the Principal Reference to their Industrial Origin

Processes Involving Risk. London.
Levine, L., and Fahy, J. P. (1945). f. industr. Hyg., 27, 217.

Mauzerall, D., and Granick, S. (1956). 7. biol Chem. $219,435$.

Ministry of Labour (1964). Memorandum on Industrial Lead Poisoning. London.

Molyneux, M. K. B. (1964). Brit. f. industr. Med., 21, 203.

Moncrieff, A. A., Koumides, O. P., Clayton, B. E., Patrick, A. D., Renwick, A. G. C., and Roberts, G. E. (1964). Arch. Dis. Child., $39,1$.

United States Public Health Service (1963). “Lead Poisoning Screening Test Study." National Clearing-house for Poison Control Centers Bulletin, July-August.

Webster, S. H. (1941). Publ. Hlth Rep. (Wash.), 56, 1834

Williams, M. K. (1966). Brit. F. industr. Med., 23, 105.

Williams, M. K. (1967). Thesis submitted for the degree of Doctor of Medicine in the University of Oxford.

Williams, M .K., and Few, J. D. (1967). Brit. F. industr. Med., 24, 294.

Zielhuis, R. L. (1961). Brit. F. industr. Med., 18, 58. 